\title{
Prey quantity affects development, survival and reproductive attributes of Coccinella transversalis Fabricius, 1781 under laboratory conditions
}

\author{
Mahadev Bista ${ }^{1 *}$ \\ ${ }^{1}$ Department of Zoology, Siddhanath Science Campus, Tribhuvan University, Mahendranagar, Nepal \\ *Correspondence: mahadevbista2026@gmail.com
}

Received: 24 June 2020 | Revised: 19 July 2020 | Accepted: 20 July 2020

\begin{abstract}
This study assessed development, survival and reproductive parameters of a ladybird beetle, Coccinella transversalis Fabricius, 1781 on different quantities (viz. scarce, optimum and abundant) of the bean aphid prey, Aphis craccivora under laboratory conditions $\left(27 \pm 1^{\circ} \mathrm{C}\right.$; $65 \pm 5 \%$ relative humidity and 14 light: 10 dark hours photoperiod). The pre-oviposition period was the shortest (6.40 \pm 0.40 days) on abundant prey and longest ( $9.20 \pm 0.49$ days) on scarce prey. The oviposition period significantly increased with increasing prey quantity, being longest (55.10 \pm 1.75 days) on abundant prey and shortest (38.50 \pm 2.14 days) on scarce prey. Lifetime fecundity and egg viability were recorded the highest (1604.10 \pm 45.61 eggs and $90.82 \pm 0.80 \%$, respectively) on abundant diet and lowest (794.60 \pm 30.84 eggs and $82.72 \pm 0.67 \%$, respectively) on scarce diet. Reproductive rate, reproductive time ratio, longevity of male and female were all highest, i.e. $29.20 \pm 0.61$ egg/day, $3.70 \pm 0.26,65.80 \pm 1$ days and $70.30 \pm 1.30$ days, respectively on abundant diet. These parameters were lowest, i.e. $20.90 \pm 0.83$ eggs/day, $1.95 \pm 0.16,58.80 \pm 1.60$ days and $56.20 \pm 1.75$ respectively on scarce diet. Development was fastest on abundant prey followed by optimum and slowest on scarce prey. Percentage pupation, percent adult emergence, developmental rate, growth index and generation survival were all highest, i.e. $84.00 \pm 3.68 \%, 79.00 \pm 4.09 \%, 0.077 \pm 0.00$ day $^{-1}, 3.50 \pm 0.19$ day $^{-1}, 0.54 \pm 0.05$, respectively when larvae were reared on abundant prey. The same parameters were lowest, i.e. $65.00 \pm 04.79 \%, 57.00 \pm 4.99 \%, 0.062 \pm 0.001$ day $^{-1}, 10.46 \pm 0.11$ day $^{-}$ ${ }^{1}, 0.25 \pm 0.0$, respectively on scarce prey. It may therefore be concluded that the availability of abundant prey enhances developmental and reproductive parameters of $C$. transversalis, and abundant diet of aphid prey may be used for better mass culture of ladybird beetles in laboratories for augmentative biological control of aphids.
\end{abstract}

Keywords: Aphid, Biocontrol, Fecundity, Ladybirds, Prey species

\section{1 | Introduction}

Food availability in environment is often heterogeneous in space and time. Its deprivation has severe effects on life attributes of insects (Santos-Cividanes et al. 2011, Singh et al. 2019). The amount and quality of food influences directly the biological aspects of beetles (Dixon 2000). When ingested food is limited or of poor quality, the development time usually increases and the reproductive rates like oviposition, fecundity and fertility decrease (Hodek et al. 2012). This is particularly true for ladybird beetles that forage in unstable habitats with variable prey density (Honek 1980, Agarwala et al. 2001). The ladybird beetles predate on a large number of aphid species that inhabit different host plants, and vary in density depending upon the geographical distribution and the seasons (Winder et al. 1994). Although these predators usually aggregate in patches of high prey abundance
(Evans \& Youssef 1992), the short-lived aphid colonies undergo rapid changes in density due to individual or combined actions of natural enemies, deterioration in host quality or the climatic changes (Agarwala \& Bardhanroy 1999). Predaceous ladybird beetles are highly dependent on prey quality and availability for their sustenance. Their food range may be classified as essential (prey that support immature growth and adult reproduction) or alternative (prey that only maintain the predator when essential prey is not available) (Hodek \& Honek 1996). The dependency on alternative prey like conspecific/ heterospecific eggs or pollen may have negative effects on the life attributes of female and her progeny (Hattingh \& Samways 1992, Jalali et al. 1999, Kumar et al. 2014). However, the effects may be more severe in absence of alternative prey, and may include retardation of vital processes in the predator and/ or cause their mortality (Jalali et al. 1999). 
Clutch size and oviposition rates are known to be influenced by the availability of prey quantity to the females at the time of oviposition (Dixon \& Guo 1993, Dixon 2000), and are maximum when females are reared on abundant prey (Ware et al. 2008). The development of offspring is influenced by both the nutrient reserve in eggs and the food provided to them during development (Singh et al. 2019, 2020). Prey deprivation severely affects the development and survival of ladybirds (Omkar \& Pervez 2003, Singh et al. 2016). It is believed that under prey scarce conditions, the energy resources are utilized to maximize the survival and reproduction (Legaspi \& Legaspi 1998). During prey scarcity, a female is likely to devote all of her resources that she obtains from the relatively few preys consumed to her own self-maintenance, and use some of the energy and nutrients to initiate the egg production (Omkar \& Pervez 2003). Individuals that acquire abundant prey from a resource rich environment may benefit by transferring their resources to their offspring, thus enhancing the offspring fitness (Qvarnström \& Price 2001, Bonduriansky \& Head 2007). Moreover, females invest a limited degree in egg production even in absence of aphid prey, to enhance their ability to oviposit quickly upon locating the patches of high aphid density (Singh et al. 2019). It appears that females use the resources from limited prey consumption to support the modest egg production.

Aphids are the most destructive and widely distributed herbivorous insect pests that are predominantly found in both temperate and tropical climatic regions of the world (Nelson \& Rosenheim 2006) including India (Ghosh 1974) and Nepal (Sharma 2000, Thapa 2015). They cause damages directly by sucking the plant sap, secrete honeydew resulting in development of sooty mould on leaves and shoots, and indirectly as vectors of plant viruses (Kennedy et al. 1962, Raboudi et al. 2002). The ladybird beetles are of great economic importance in agroecosystems through their successful application in the biological control of many injurious insects (Agarwala \& Dixon 1992).

Coccinella transversalis Fabricius, 1781 is a predaceous ladybird beetle of the Oriental region, native to India and abundant in all the countries of south Asia (Omkar \& Pervez 2000). The beetle has black head with two yellow patches on either side of the middle line, the pronotum is black with two yellowish to red spots at the anterior end. A black stripe runs down the middle line connecting the two elytra and is broadened at the anterior end to form a dot like structure. Each elytron possesses three transverse wavy black stripes against a reddish background. In the Indian subcontinent, the beetle is found actively feeding on aphids from December to April, being relatively abundant in December and January, and during mid-March. The beetle becomes active again from July to September (Chakraborty \& Korat 2014). The beetle inhabits both urban and rural areas feeding on aphids. It is commonly found predating on aphids, like Aphis craccivora, Aphis gossypii and Lipaphis erysimi in agricultural and horticultural fields (Omkar \& Bind 1993), and is one of the important members of the local predator complex. The wide prey range and acceptance of a variety of aphid species, make this species as a potential biocontrol agent in aphid management programs.

The present investigation has therefore been designed to evaluate the effect of quantity of food on the growth, development and reproduction of $C$. transversalis. This information can be exploited for rapid mass multiplication of $C$. transversalis in laboratories. The result may be helpful in developing future Integrated Pest Management (IPM) approaches for augmentative biocontrol of aphids on various agricultural crops of Nepal.

\section{2 | Materials and methods}

\section{1 | Establishment of stock culture}

Adults of C. transversalis $(n=100)$ were collected by the handpicking method from bean plants (Dolichos lablab; Fabaceae)

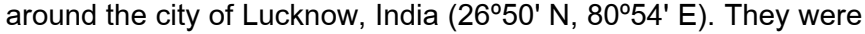
brought to laboratory of Department of Zoology, Lucknow University to establish the stock in environmental test chamber at optimum abiotic conditions, i.e. $27 \pm 1^{\circ} \mathrm{C} ; 65 \pm 5 \% \mathrm{RH}$ and $14 \mathrm{~L}$ : $10 \mathrm{D}$ light: dark hour photoperiod. They were supplied with the bean aphid, A. craccivora infested on bean plants reared in greenhouses (at $28 \pm 1^{\circ} \mathrm{C} ; 65 \pm 5 \%$ relative humidity and $14 \mathrm{~L}: 10 \mathrm{D}$ ). The adults were paired in plastic Petri dishes $\left(14.5 \times 1.5 \mathrm{~cm}^{2}\right)$. The aphid supply was replenished every $24 \mathrm{~h}$ and the oviposition, if any, was recorded, after which mating pairs were transferred to new dishes. The Petri dishes containing eggs were observed for hatching and the newly emerged larvae were reared in beakers $\left(14.5 \times 10.5 \mathrm{~cm}^{2}\right)$ on daily replenishment of an exclusive ad libitum supply of the aphid species provided to the parents

\section{2 | Experimental design}

Adults of C. transversalis were selected from the main stock culture for the maintenance of sub-culture. Prior to the 
experimentation, ten females of each species were reared on 50 $\mathrm{mg}$ aphids/ female for $24 \mathrm{~h}$ to standardize the optimum quantity of prey consumed. Supply of $25 \mathrm{mg}$ aphids/ female was considered for the scarce condition whereas supply of $75 \mathrm{mg}$ aphids/ female was treated as abundant prey condition. Similar standardization of the prey quantity was done for the larval instars. Males and females were paired in separate Petri dishes $\left(9.0 \times 1.5 \mathrm{~cm}^{2}\right)$ on daily replenishment of one of the three different quantities of aphid prey conditions, viz. scarce $(25 \mathrm{mg})$, optimal $(50 \mathrm{mg})$ and abundant $(75 \mathrm{mg})$ for a generation and the resultant F1 larvae were used in experiments (see Bista \& Omkar 2014). They were kept at abiotic conditions similar to the main stock (27 $\pm 1^{\circ} \mathrm{C}$; $65 \pm 5 \% \mathrm{RH}$; $14 \mathrm{~L}$ : $10 \mathrm{D}$ photoperiod) and were provided with the quantity of prey similar to their parents replenished every 24 hours. All experiments were conducted on environmental conditions similar to that in the stock culture.

\section{a. Effect of prey quantity on reproductive attributes}

To investigate the effects of prey quantity on reproduction, sexually mature adult males and females of C. transversalis, obtained from each of the scarce, optimal and abundant prey conditions were paired in plastic Petri dishes and allowed to mate for lifetime under the optimum abiotic conditions similar to the main stock (i.e. $27 \pm 1^{\circ} \mathrm{C}$; $65 \pm 5 \% \mathrm{RH}$; 14L: 10D photoperiod). Aphid prey was replenished every day. Oviposition was recorded and all the observations were taken every 24 hours. Daily fecundity, percent egg viability, pre-oviposition, oviposition, postoviposition periods and longevity of adults were recorded. Reproductive rate (Fecundity/oviposition period) and reproductive time ratio (reproductive period/non reproductive period) was also calculated.

\section{b. Effect of prey quantity on offspring development and survival}

To investigate the effects of quantity of prey on offspring development and survival, eggs laid by the females in the above experiment were collected and their incubation period was recorded. One hundred first instar larvae (zero day old) were randomly selected from each of the scarce, optimal and abundant prey conditions. The larvae were reared in the petri dishes $(9.0 \times$ $1.5 \mathrm{~cm}^{2}$ ) (single larva/ Petri dish) under prey scarce (25 mg/ larva/ day), optimal (50 mg/ larva/ day) and abundant ( $75 \mathrm{mg} /$ larva/ day) conditions. The aphid supply was replenished every $24 \mathrm{~h}$, and the observations were made. When ecdysis occurred, duration of each instar and their survival were recorded. Thereafter, pre-pupal and pupal periods along with their survival were recorded. The experiment was performed in 10 replicates. Percentage pupation (number of pupae $\times 100 /$ number of first instars hatched), adult emergence (number of adults emerged $x$ $100 /$ number of pupae), development rate (1/developmental period, i.e. the period from the day of oviposition to adult emergence), generation survival (Number of female emerged/number of first instar) and growth index (i.e. ratio of percentage pupation and mean larval duration) were calculated following Dubey et al. (1981).

\section{3 | Statistical analysis}

Data obtained on various reproductive and developmental parameters were subjected to one-way ANOVA followed by Tukey's post-hoc comparison of means. All data were checked for normal distribution using Bartlett's test for normality prior to being subjected to one-way ANOVA followed by post hoc Tukey's significance test at $5 \%$ level. All percent data were subjected to arcsine square root transformation prior to ANOVA. The age specific fecundity graphs were plotted. All statistical analyses were performed on MINITAB 16 (Minitab Inc., State College, Pennsylvania, USA).

\section{3 | Results}

\section{1 | Effect of prey quantity on reproductive attributes}

Data on reproductive attributes of $C$. transversalis expressed in pre-oviposition, oviposition and postoviposition periods, fecundity, percentage viability of eggs, mean reproductive rate, reproductive time ratio and adult longevities when fed on three different food quantities are presented in Table 1. Significant variations in preoviposition period $(F=10.87 ; P<0.0001)$, oviposition period $(F=$ 24.88; $P<0.0001)$, post oviposition period $(F=4.02 ; P=0.030)$, fecundity ( $F=123.32 ; P<0.0001)$ and percentage viability of eggs $(F=27.73 ; P<0.0001)$ were recorded. All these parameters were recorded highest on abundant prey condition and minimum on scarce prey conditions. The mean reproductive rate of the female ladybird beetle varied significantly $(F=46.20$; $P<0.0001)$, was highest on abundant prey condition and lowest on scarce prey condition. The reproductive time ratio differed significantly $(F=$ 16.76; $\mathrm{P}<0.0001$ ) on the three prey conditions. The age specific fecundity graphs showed triangular pathways (Fig. 1). Interpretation of graphs through calculated measures revealed 
statistically significant changes $(F=210.85 ; P<0.0001)$ in oviposition rate at peak with change in prey quantities. The peak of oviposition was high on abundant prey and low on scarce prey condition (Fig. 1). The longevity of male ( $F=10.25 ; P$ $<0.0001)$ and female $(F=21.72 ; \mathrm{P}<0.0001)$ ladybird beetles varied significantly with maximum on abundant prey condition and minimum on scarce prey condition

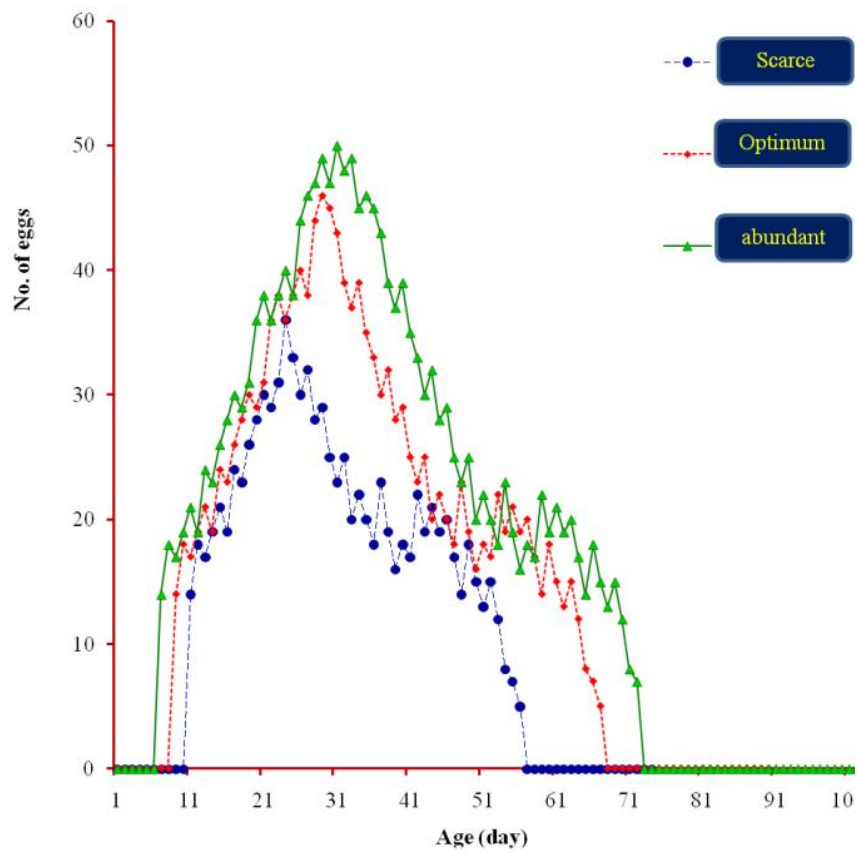

Figure 1. Effect of prey quantity on age specific fecundity of adult $C$. transversalis.

\section{2 | Effect of prey species on offspring development and} survival

The duration of different life stages of $C$. transversalis when provided with three different prey conditions are listed in Fig. 2. The significant effect of prey quantity was observed on all the life stages when the larval instars were fed with three different quantities of food. This included incubation period $(F=11.26$; $P<0.0001)$, first $(F=35.00 ; P<0.0001)$, second $(F=24.92 ; P$ $<0.0001)$, third $(F=26.41 ; P<0.0001)$ and fourth instar $(F=$
13.86; $\mathrm{P}<0.0001)$, pre-pupal $(\mathrm{F}=6.02 ; \mathrm{P}=0.003)$ and pupal periods $(F=6.88 ; P<0.001)$. The total developmental period differed significantly $(F=94.56 ; P<0.0001)$, and was minimum on abundant and maximum on scarce prey condition. Significant difference was also observed in percent pupation $(F=5.46$; $\mathrm{P}=0.005)$, percent adult emergence $(F=6.94 ; \mathrm{P}<0.001)$, developmental rate $(F=70.86 ; \mathrm{P}<0.0001)$, generation survival $(F=6.78 ; P<0.001)$ and growth index $(F=51.59 ; P<0.0001)$ (Table 2). Thus, the results suggested that abundant prey quantity increased the growth, development and immature survival of $C$. transversalis

\section{4 | Discussion}

Growth, development and reproduction of ladybird beetles are closely associated with the quantity of aphid prey offered (Singh et al. 2020). Results of this study revealed that the nonreproductive (pre- and post-oviposition) periods were shortest, whereas reproductive or oviposition periods and longevity of males and females were the longest under the abundant prey condition. Fecundity, egg fertility and reproductive rates were also highest when prey was abundantly available and lowest on scarcity condition. Experimental and field studies indicate that there is a density of aphids below which ladybirds are unlikely to lay eggs (Dixon 2000, Das \& Dixon 2011, Singh et al. 2019). Absence of reproduction under prey scarcity condition (during late summers from May to July) is common among ladybirds when the energy goes to survival (McNamara \& Buchanan 2005, Britto et al. 2009, Singh et al. 2020). Thus, the rate of reproductive maturation and fecundity are sensitive both to the quality and quantity of prey (Reznik \& Vaghina 2012, Chaudhary et al. 2016). The longer pre-oviposition and shorter oviposition period under prey deprived condition may be attributed to late ripening of ovarioles due to non-availability of sufficient prey. Yasar and Ozger (2005) observed that increasing Hyalopterus pruni density

Table 1. Effect of prey quantity on reproductive attributes of $C$. transversalis (Values are Mean \pm S.E; ${ }^{* *}$ denote F-values to be significant at $P$ <0.01, (d.f. = 2, 29); NS denotes F-values to be non-significant at $\mathrm{P}>0.05$; Values followed by different alphabets show significant differences) (also see Bista \& Omkar 2014).

\begin{tabular}{|c|c|c|c|c|c|c|c|c|c|}
\hline $\begin{array}{l}\text { Prey } \\
\text { quantity }\end{array}$ & $\begin{array}{l}\text { Pre- } \\
\text { oviposition } \\
\text { (days) }\end{array}$ & $\begin{array}{l}\text { Oviposition } \\
\text { (days) }\end{array}$ & $\begin{array}{l}\text { Post- } \\
\text { oviposition } \\
\text { (days) }\end{array}$ & $\begin{array}{l}\text { Fecundity } \\
\text { (No. of eggs) }\end{array}$ & $\begin{array}{l}\text { Percent } \\
\text { viability }\end{array}$ & $\begin{array}{l}\text { Reproductive } \\
\text { rate (egg/day) }\end{array}$ & $\begin{array}{l}\text { Reproductive } \\
\text { time ratio }\end{array}$ & $\begin{array}{l}\text { Female } \\
\text { longevity } \\
\text { (days) }\end{array}$ & $\begin{array}{l}\text { Male } \\
\text { longevity } \\
\text { (days) }\end{array}$ \\
\hline Scarce & $9.20 \pm 0.49^{b}$ & $38.50 \pm 2.14^{\mathrm{a}}$ & $11.10 \pm 0.71^{b}$ & $794.60 \pm 30.84^{\mathrm{a}}$ & $82.72 \pm 0.67^{a}$ & $20.90 \pm 0.83^{\mathrm{a}}$ & $1.95 \pm 0.16^{\mathrm{a}}$ & $58.80 \pm 1.60^{\mathrm{a}}$ & $56.20 \pm 1.75^{a}$ \\
\hline Optimum & $7.00 \pm 0.45^{a}$ & $52.70 \pm 1.61^{\mathrm{ab}}$ & $10.10 \pm 0.55^{\mathrm{ab}}$ & $1561.30 \pm 44.91^{b}$ & $89.87 \pm 0.87^{b}$ & $29.71 \pm 0.72^{b}$ & $3.17 \pm 0.23^{b}$ & $69.80 \pm 1.26^{b}$ & $64.20 \pm 1.58^{b}$ \\
\hline Abundant & $6.40 \pm 0.40^{\mathrm{a}}$ & $55.10 \pm 1.75^{b}$ & $8.80 \pm 0.44^{a}$ & $1604.10 \pm 45.61^{b}$ & $90.82 \pm 0.80^{b}$ & $29.20 \pm 0.61^{b}$ & $3.70 \pm 0.26^{b}$ & $70.30 \pm 1.30^{b}$ & $65.80 \pm 1.48^{b}$ \\
\hline F-value & $10.87^{* *}$ & $24.88^{* *}$ & $4.02^{*}$ & $123.32^{* *}$ & $27.73^{\text {** }}$ & $46.20^{* *}$ & $16.76^{\star *}$ & $21.72^{* *}$ & $10.25^{\star *}$ \\
\hline
\end{tabular}




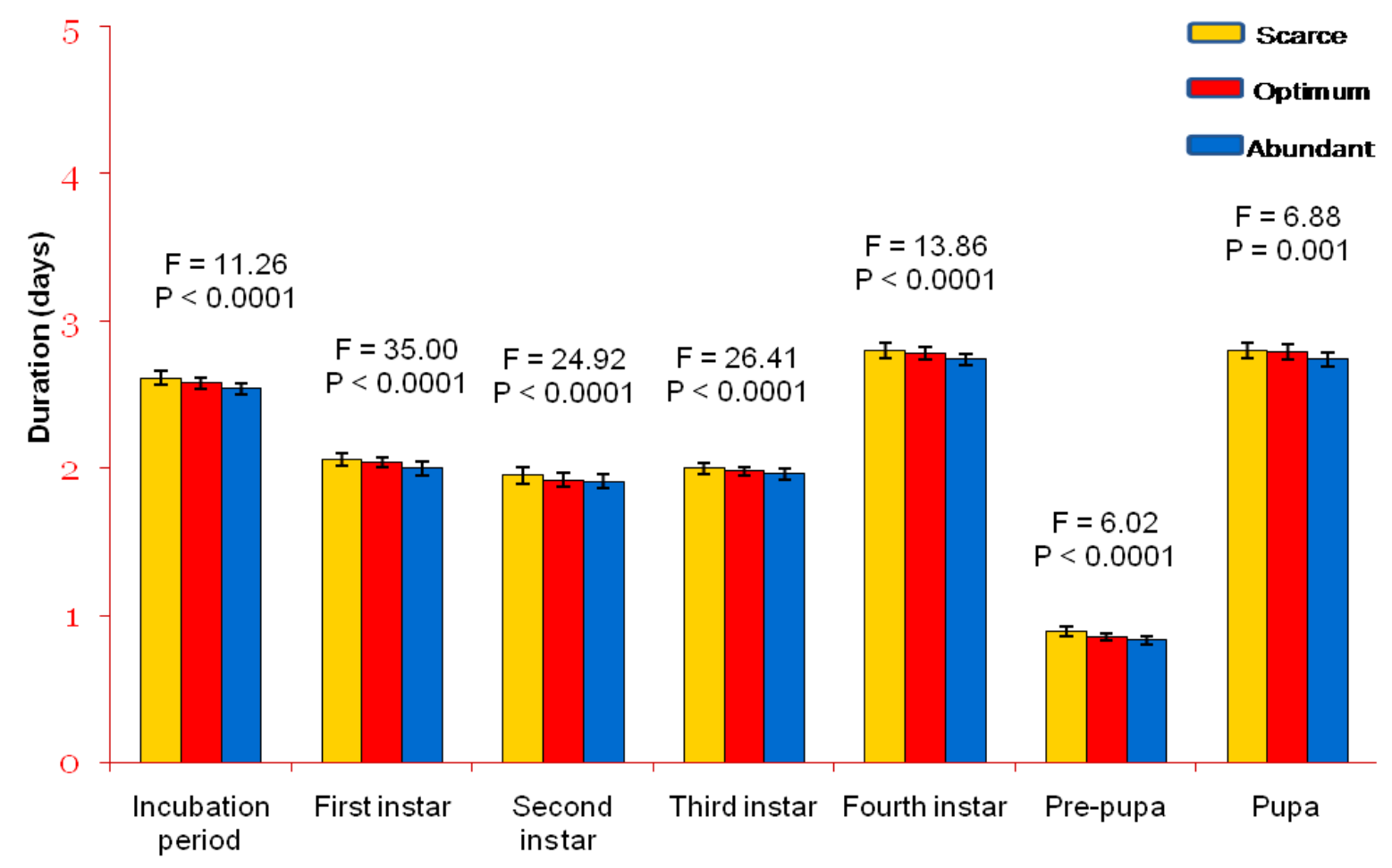

\section{Developmental stages}

Figure 2. Effect of prey quantity on development of immature stages of $C$. transversalis

as prey resulted in shorter preovipositional period in Adalia fasciatopunctata revelierei. Omkar and Pervez (2003) also reported that the pre-oviposition period of female Propylea disecta increased with increase in the duration of prey deprivation. The finding agrees with the optimal foraging theory, which states that females desist from laying eggs in habitats that cannot support progeny survival (Kindlmann \& Dixon 1993, Singh et al. 2016).

Results further revealed that the prey quantity is directly proportional to the fecundity and egg viability. The lowest fecundity and egg viability were observed under prey scares condition and highest on abundant prey condition. Such prey abundant conditions are generally observed in the agricultural farms from late November (winters) till March (spring). The longevity of adults of $C$. transversalis decreased under prey scarce conditions. The decrease in fecundity, egg viability and longevity under prey scarce condition may be attributed to the non-availability of sufficient prey quantity or due to nutritional deficiency. Studies on the effect of prey quantity on the longevity and fecundity of other predators are also in agreement with the present findings (Yasar \& Ozger 2005, Agrawala et al. 2008). Studies have shown that the reproductive rate decreases under the scarcity or unavailability of aphid prey (Omkar et al. 2010). Under prey scarce or prey deprived conditions, instead of reproduction ladybirds invest most of their energy for their maintenance and survival, since reproduction is a costly process (Dixon 2000), or the reproduction may be ceased. The findings of the present study are also in agreement with those reported by Atlihan and Guldal (2009) in ladybird beetle Scymnus subvillosus.

Table 2. Effect of prey quantity on immature development and survival parameters of $C$. transversalis. (Values are Mean \pm S.E; ${ }^{* *}$ denote F-values to be significant at $\mathrm{P}<0.01$, (d.f. = 2, 29); NS denotes Fvalues to be non-significant at $P>0.05$; Values followed by different alphabets show significant differences) (also see Bista \& Omkar 2014).

\begin{tabular}{|l|l|l|l|l|l|}
\hline $\begin{array}{l}\text { Prey } \\
\text { quantity }\end{array}$ & $\begin{array}{l}\text { Percent } \\
\text { pupation (\%) }\end{array}$ & $\begin{array}{l}\text { Percent adult } \\
\text { emergence (\%) }\end{array}$ & $\begin{array}{l}\text { Development } \\
\text { al rate (day }\end{array}$ & $\begin{array}{l}\text { Growth }) \\
\text { (day }^{-1} \text { ) }\end{array}$ & $\begin{array}{l}\text { Generation } \\
\text { survival }\end{array}$ \\
\hline Scarce & $65.00 \pm 04.79^{\mathrm{a}}$ & $57.00 \pm 4.99^{\mathrm{a}}$ & $0.062 \pm 0.001^{\mathrm{a}}$ & $10.46 \pm 0.11^{\mathrm{a}}$ & $0.25 \pm 0.04^{\mathrm{a}}$ \\
\hline Optimum & $79.00 \pm 4.09^{\mathrm{b}}$ & $73.00 \pm 4.46^{\mathrm{b}}$ & $0.073 \pm 0.001^{\mathrm{b}}$ & $12.68 \pm 0.25^{\mathrm{b}}$ & $0.45 \pm 0.05^{\mathrm{b}}$ \\
\hline Abundant & $84.00 \pm 3.68^{\mathrm{b}}$ & $79.00 \pm 4.09^{\mathrm{b}}$ & $0.077 \pm 0.001^{\mathrm{c}}$ & $13.50 \pm 0.19^{\mathrm{c}}$ & $0.54 \pm 0.05^{\mathrm{b}}$ \\
\hline F-value & $\mathbf{5 . 4 6 ^ { \star * }}$ & $\mathbf{6 . 9 4}^{\star *}$ & $\mathbf{7 0 . 8 6}^{\star *}$ & $\mathbf{5 1 . 5 9}^{\star *}$ & $\mathbf{6 . 7 8}^{\star *}$ \\
\hline
\end{tabular}


C. transversalis exhibited triangular fecundity function i.e. daily oviposition initially increased with age to a peak, and then declined with further increase in age (Dixon \& Agarwala 2002). The peak in oviposition occurred earlier in adult life under favourable conditions when prey availability is abundant. Difference between the time of peak oviposition indicate the age specific fecundity is prey quantity dependant. The results are similar to those reported by Dehkordi et al. (2013) in Hippodamia variegata.

Incubation periods, durations of larval instars, pre-pupal and pupal periods and total developmental durations were shortest under prey abundant conditions and longest under prey scarce conditions. Studies have shown that optimal amount of suitable aphid prey in the form of parental diet is necessary for the development of embryos (Omkar \& Srivastava 2003, Pervez \& Omkar 2004, Omkar et al. 2010, Sun et al. 2017). Such a slowing down of larval development under prey scarce conditions may be ascribed to the decreased availability of nutrition. Pervez and Omkar (2004) have reported that consumption of aphid prey in lesser quantity resulted in delayed moulting and pupation, thereby increasing total developmental periods of larvae and ultimately reducing their fitness levels. Effects of prey quantity on larval development, revealing similar results have earlier been reported in ladybirds on aphid prey (Agarwala et al. 2008, Atlihan \& Guldal 2009, Chaudhary et al. 2016, Singh et al. 2020). It is inferred that the life history traits of ladybird beetle change in response to nutrient stress. However, the successful development of both larvae and adults under food stressed conditions suggest the occurrence of strong selection pressure in natural population of ladybird beetles for survival and reproduction even under adverse conditions.

\section{Conclusions}

Based on the results of the present study, it may be concluded that the availability of abundant prey conditions causes higher reproductive performances in ladybirds. The developmental durations of immature stages decrease and the larvae have maximum survival rates with least mortality when reared on abundant prey. On the contrary, scarce prey conditions induce poor reproductive performances in adult ladybird beetles, and cause the slower development with higher mortality in their offspring. Hence, for successful mass multiplication of ladybird predators in laboratories, abundant prey condition should be provided

\section{Acknowledgements}

The author is thankful to UGC, Nepal for providing financial assistance in the form of Teacher's Fellowship and to Professor Omkar, Department of Zoology, University of Lucknow, Lucknow (India) for providing laboratory facilities to conduct the study.

\section{Conflicts of interest}

Author declares no conflict of interest.

\section{ORCID}

Mahadev Bista (i) https://orcid.org/0000-0003-2130-7047

\section{References}

Agarwala, B. K. and Bardhanroy, P. 1999. Numerical response of ladybird beetles (Col., Coccinellidae) to aphid prey (Hom., Aphididae) in a field bean in north-east India. Journal of Applied Entomology 123:401-405.

Agarwala, B. K. and Dixon, A. F. G. 1992. Laboratory study of cannibalism and interspecific predation in ladybirds. Ecological Entomology 17:303-309.

Agarwala, B. K., Bardhanroy, P., Yasuda, H. and Takizawa, T. 2001. Prey consumption and oviposition of the aphidophagous predator Menochilus sexmaculatus (Coleoptera: Coccinellidae) in relation to prey density and adult size. Environmental Entomology 30:1182-1187. https://doi.org/10.1603/0046-225X-30.6.1182

Agarwala, B. K., Yasuda, H. and Sato, S. 2008. Life history response of a predatory ladybird, Harmonia axyridis (Pallas) (Coleoptera: Coccinellidae) to food stress. Applied Entomology and Zoology 43:183-189. https://doi.org/10.1303/aez.2008.183

Atlihan, R. and Guldal, H. 2009. Prey density-dependent feeding activity and life history of Scymnus subvillosus. Phytoparasitica 37:35-41.

Bista, M. and Omkar. 2014. Consumption, developmental and reproductive attributes of two congeneric ladybird predators under variable prey supply. Biological Control 74:36-44. https://doi.org/10.1016/j.biocontrol.2014.04.001

Bonduriansky, R. A. and Head, M. 2007. Maternal and paternal condition effects on offspring phenotype in Telostylinus angusticollis (Diptera: Neriidae). Journal of Evolutionary Biology 20:2379-2388. https://doi.org/10.1111/j.1420-9101.2007.01419.x

Britto, E. P. J., Gondim Jr., M. G. C., Torres, J. B., Fiaboe, K. K. M., Moraes, G. J. and Knapp, M. 2009. Predation and reproductive 
output of the ladybird beetle Stethorus tridens preying on tomato red spider mite, Tetranychus evansi. Biocontrol 54:363-368.

Chakraborty, D. and. Korat, D. M. 2014. Population dynamics of Coccinella transversalis Fabricius in relation to weather parameters. The Ecoscan 8:141-147.

Chaudhary, D. D., Kumar, B., Mishra, G. and Omkar 2016. Effects of prey resource fluctuation on predation attributes of two sympatric Coccinellidae (Coleoptera). The Canadian Entomologist 148:443-451. https://doi.org/10.4039/tce.2015.73

Das, B. C. and Dixon, A. F. G. 2011. Assessment of patch quality by aphidophagous ladybirds: Laboratory study on the minimum density of aphids required for oviposition. European Journal of Environmental Science 1:57-60.

Dehkordi, S. D., Sahragard, A. and Hajizadeh, J. 2013. The effect of prey density on life table parameters of Hippodamia variegata (Coleoptera: Coccinellidae) fed on Aphis gossypii (Hemiptera: Aphididae) under laboratory conditions. International Scholarly Research Notices. https://doi.org/10.1155/2013/281476

Dixon, A. F. G. 2000. Insect predator-prey dynamics: ladybird beetles and biological control. Cambridge University Press, Cambridge.

Dixon, A. F. G. and Agarwala, B. K. 2002. Triangular fecundity function and ageing in ladybird beetles. Ecological Entomology 27:433440. https://doi.org/10.1046/j.1365-2311.2002.00429.x

Dixon, A. F. G. and Guo, Y. 1993. Egg and cluster-size in ladybird beetles (Coleoptera, Coccinellidae)-the direct and indirect effects of aphid abundance. European Journal of Entomology 90:457-463.

Dubey, A. K., Misra, V. S. and Dixit, S. A. 1981. Effect of host plant on the developmental stages of Heliothis armigera. Indian Journa of Entomology 29:48-57.

Evans, E. W. and Youssef, N. N. 1992. Numerical responses of aphid predators to varying prey density among Utah alfalfa fields. Journal of the Kansas Entomological Society 65:30-38.

Ghosh, A. K. 1974. New species and new records of aphids (Homoptera : Aphididae) from Northeast India. Oriental Insects 8:161-175

Hattingh, V. and Samways M. J. 1992. Prey choice and substitution in Chilocorus spp. (Coleoptera: Coccinellidae). Bulletin of Entomological Research 82:375-334.

Hodek, I. and Honek, A. 1996. Ecology of Coccinellidae. Kluwer Academic Publishers (Dordrecht, Boston, London), the Netherlands.

Hodek, I., van Emden, H. F. and Honek, A. 2012. Ecology and behavior of the ladybird beetles (Coccinellidae). Blackwell Publishing limited, UK
Honek, A. 1980. Population density of aphids at the time of settling and ovariole maturation in Coccinella septempunctata (Col.: Coccinellidae). Entomophaga 25:427-430.

Jalali S. K., Singh S. P. and Biswas S. R. 1999. Effect of temperature and female age on the development and progeny production of Cryptolaemus montrouzieri Mulsant (Coleoptera: Coccinellidae). Entomon 24:293-29.

Kennedy, J. S., Day, M. F. and Eastop, V. F. 1962. A Conspectus of Aphids as Vectors of Plant Viruses, Commonwealth Institute of Entomology, London, UK.

Kindlmann, P. and Dixon, A. F. G. 1993. Optimal foraging in ladybird beetles (Coleoptera: Coccinellidae) and its consequences for their use in biological control. European Journal of Entomology $90(4): 443-450$.

Kumar, B., Bista, M., Mishra, G. and Omkar 2014. Stage specific consumption and utilization of aphids, conspecific and heterospecific eggs by two species of Coccinella (Coleoptera: Coccinellidae). European Journal of Entomology 111:363-369. https://doi.org/10.14411/eje.2014.046

Legaspi, J. C. and Legaspi, B. C. 1998. Life history trade-offs in insects, with emphasis on Podisus maculiventris (Heteroptera: Pentatomidae). In: M. Coll and J.R. Ruberson (eds), Predatory Heteroptera: Their ecology and use in biological control. Thomas Say Publications in Entomology, Laham.

McNamara, J. M. and Buchanan, K. L. 2005. Stress, resource allocation, and mortality. Behavioural Ecology 16:1008-1017. https://doi.org/10.1093/beheco/ari087

Nelson, E. H. and Rosenheim J. A. 2006. Encounters between aphids and their predators: the relative frequencies of disturbance and consumption. Entomologia Experimentalis et Applicata 118:211219. https://doi.org/10.1111/j.1570-7458.2006.00378.x

Omkar and Bind, R. B. 1993. Records of aphid-natural enemies complex of Uttar Pradesh. II. The Coccinellids. Journal of Advances in Zoology 14:96-99.

Omkar and Pervez, A. 2000. Sexual dimorphism in Propylea dissecta (Mulsant), (Coccinellidae: Coleoptera). Journal of Aphidology, 14:139-140.

Omkar and Pervez, A. 2003. Influence of prey deprivation on biological attributes of pale morphs of the ladybeetle, Propylea dissecta (Mulsant). Insect Science and Its Applications 23:143-148. https://doi.org/10.1017/S1742758400020361

Omkar and Srivastava, S. 2003. Comparative prey consumption and searching efficiency of ladybeetles, Coccinella septempunctata Linnaeus and Coccinella transversalis Fabricius for different aphid species. Journal of Biological Control 17:35-41.

Omkar, Sahu, J. and Kumar, G. 2010. Effect of prey quantity in a ladybird beetle, Anegleis cardoni (Weise) (Coleoptera: 
Coccinellidae). International Journal of Tropical Insect Science 30:48-56. https://doi.org/10.1017/S1742758410000056

Pervez, A. and Omkar 2004. Prey-dependent life attributes of an aphidophagous ladybird beetle, Prsopylea dissecta (Coleoptera: Coccinellidae). Biocontrol Science and Technology 14:385-396. https://doi.org/10.1080/09583150410001683547

Qvarnström, A. and Price, T. D. 2001. Maternal effects, paternal effects and sexual selection. Trends in Ecology and Evolution 16:95-100

Raboudi, F., Ben Moussa A., Makni, H., Marrakchi, M. and Makni, M. 2002. Seriological detection of plant viruses in their aphid vectors and host plants in Tunisia. EPPO Bulletin 32:495-498.

Reznik, S. Ya. and Vaghina, N. P. 2012. Effects of photoperiod and diet on diapause tendency, maturation and fecundity in Harmonia axyridis (Coleoptera: Coccinellidae). Journal of Applied Entomology 137:452-461. https://doi.org/10.1111/jen.12016

Santos-Cividanes, T. M., dos Anjos, A. C. R., Cividanes, F. J. and Dias, P. C. 2011. Effects of food deprivation on the development of Coleomegilla maculata (De Geer) (Coleoptera: Coccinellidae). Neotropical Entomology 40:112-116. https://doi.org/10.1590/S1519-566X2011000100017

Sharma, K. C. 2000. Aphids of Nepal. Sajha Prakashan Publication House Nepal.

Singh, N., Mishra, G. and Omkar. 2016. Slow and fast development in two aphidophagous ladybirds on scarce and abundant prey supply. Bulletin of Entomological Research 106:347-358. https://doi.org/10.1017/S0007485316000080

Singh, P., Mishra, G. and Omkar. 2020. Are the effects of hunger stage-specific? A case study in an aphidophagous ladybird beetle. Bulletin of Entomological Research. https://doi.org/$10.1017 /$ S0007485320000309

Singh, S., Mishra, G. and Omkar. 2019. Oviposition in aphidophagous ladybirds: effect of prey availability and conspecific egg presence. International Journal of Tropical Insect Science 39:107-114. https://doi.org/10.1007/s42690-019-000069

Sun, Y. X., Hao, Y. N., Riddick, E. W. and Liu, T. X. 2017. Factitious prey and artificial diets for predatory lady beetles: current situation, obstacles, and approaches for improvement: a review. Biocontrol Science and Technology 27:601-619. https://doi.org/10.1080/09583157.2017.1324112

Thapa, V.K. 2015. Insect diversity in Nepal. Format Printing Press, Kathmandu, p 1196.

Ware, R. L., Yguel, B. and Majerus, M. E. N. 2008. Effects of larval diet on female reproductive output of the European coccinellid Adalia bipunctata and the invasive species Harmonia axyridis
(Coleoptera: Coccinellidae). European Journal of Entomology 105(3):437-443. https://doi.org/10.14411/eje.2008.056

Winder, L., Hirst, D. J., Carter, N., Wratten, S. D. and Sopp, P. I. 1994. Estimating predation of the grain aphid Sitobion avenae by polyphagous predators. Journal of Applied Ecology 31:1-12. https://doi.org/10.2307/2404594

Yasar, B. and Ozger, S. 2005. Development, feeding and reproduction responses of Adalia fasciatopunctata (Mulsant) (Coleoptera: Coccinellidae) to Hyalopterus pruni (Geoffroy) (Homoptera: Aphididae). Journal of Pest Science 78(4):199-203. https://doi.org/10.1007/s10340-005-0089-2

\section{Cite this article as:}

Bista, M. 2020. Prey quantity affects development, survival and reproductive attributes of Coccinella transversalis Fabricius, 1781 under laboratory conditions. Nepalese Journal of Zoology 4(1):8-15. https://doi.org/10.3126/njz.v4i1.30668 